Check for updates

Cite this: RSC Adv., 2019, 9, 19075

Received 11th May 2019

Accepted 8th June 2019

DOI: 10.1039/c9ra03537k

rsc.li/rsc-advances

\section{Colour-tunable ultralong organic phosphorescence upon temperature stimulus $\uparrow$}

\author{
Zuoji Niu,,$^{\mathrm{ab}}$ Chaoqun Ma, $\dot{t}^{\mathrm{b}}$ Wenpeng Ye, ${ }^{\mathrm{b}}$ He Wang, ${ }^{\mathrm{b}}$ Wenyong Jia, ${ }^{\mathrm{b}}$ Huixian Shi, ${ }^{\text {*a }}$ \\ Huifang Shi, ${ }^{* b}$ Zhongfu An (D) ${ }^{* b}$ and Wei Huang ${ }^{b}$
}

A new class of single-component molecular crystal with colour-tunable ultralong organic phosphorescence (UOP) was designed and synthesized through alkyl chain engineering. Forming a more rigid environment at $77 \mathrm{~K}$, the colour-tunable UOP from yellow-white to blue-green is achieved through dual-emission of crystal and amorphous states.
Ultralong phosphorescence, a kind of phosphorescence that can be observed by the naked eye after removing the excitation source, has received great attention in the fields of sensing, ${ }^{1}$ displays, ${ }^{2}$ imaging, ${ }^{3}$ anti-counterfeiting ${ }^{4}$ and so on during the past years. Unfortunately, it is limited to inorganic materials because of the weak spin-orbit coupling (SOC) and strong non-radiative transition of pure organic materials. ${ }^{5}$ Compared with inorganic materials, however, organic materials have some excellent merits, such as inexpensive cost, relative safety to the environment, and soft preparation conditions. ${ }^{6}$ The realization of UOP becomes very significant. As mentioned above, UOP can be achieved by promoting intersystem crossing (ISC) through enhancing SOC and suppressing non-radiative transitions. In view of these factors, various strategies such as polymerization, ${ }^{7} \mathrm{H}$-aggregation, ${ }^{8}$ crystallization, ${ }^{9}$ host-guest doping, ${ }^{10}$ and freezing conditions $^{11}$ have been explored to achieve UOP with the unremitting efforts of scientific researchers.

Intelligent-response organic luminescent materials can change their luminescent properties such as colour, lifetime, intensity, etc. after being stimulated by the external factor, such as mechanical forces, temperature, $\mathrm{pH}$, light, solvent, etc., which have caught great attraction. The sensitivity of luminescent molecule to excitation wavelength, temperature or oxygen can be applied in sensors, optical recording and so on..$^{12-14}$

However, the luminescence of these materials with intelligent-response are mostly limited to fluorescence or room temperature phosphorescence (RTP) with relatively short

${ }^{a}$ School of Materials Science and Engineering, Taiyuan University of Technology, Taiyuan 030024, China. E-mail: freeyuan0313@163.com

${ }^{b}$ Key Laboratory of Flexible Electronics (KLOFE), Institute of Advanced Materials (IAM), Nanjing Tech University (NanjingTech), 30 South Puzhu Road, Nanjing 211816, China. E-mail:iamzfan@njtech.edu.cn

$\dagger$ Electronic supplementary information (ESI) available. CCDC 1912663 and 1912664. For ESI and crystallographic data in CIF or other electronic format see DOI: $10.1039 / \mathrm{c} 9 \mathrm{ra} 03537 \mathrm{k}$

$\$$ These authors contributed equally to this work. lifetimes. ${ }^{15-18}$ Few samples display persistent luminescent feature. ${ }^{19}$ Most organic compounds can only tune their afterglow properties by changing molecular side groups or multicomponent doping. ${ }^{20-23}$ Therefore, the development of single component UOP materials with intelligent response remains a challenge. Inspired by the alkyl-chain engineering ${ }^{24}$ and freezing conditions, herein we speculate that temperature response UOP might be induced by controlling the activity of the alkyl chain to regulate non-radiative transition rate. By means of reducing the temperature to restrict the molecular motions at amorphous state, colour-tunable UOP with temperature-response can be realized by dual-emission of molecules at both amorphous and crystalline states.

In our previous study, MCzT crystals showed yellow UOP at RT. ${ }^{25}$ The crystals showed the same UOP at $77 \mathrm{~K}$ with that at RT (Fig. 1a). Here, 9-(2-((4,6-dimethoxy-1,3,5-triazin-2-yl)oxy)ethyl)$9 H$-carbazole (MTOD) was designed and via alkyl chain attaching carbazole with a triazine core. The target molecule was characterized by ${ }^{1} \mathrm{H}$ NMR and ${ }^{13} \mathrm{C}$ NMR (Fig. S1-S3 $\dagger$ ). Its melting point reaches $130{ }^{\circ} \mathrm{C}$. (Fig. S4 $\dagger$ ) MTOD achieved a lifetime of up to $860 \mathrm{~ms}$ under ambient conditions. Surprisingly, the UOP changed from yellow-white to blue-green after the

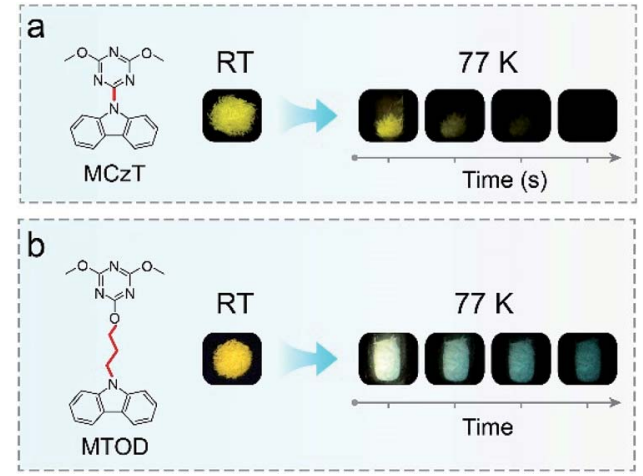

Fig. 1 Molecular structures and UOP photographs of MCzT (a) and MTOD (b). 
removal of the UV-lamp for several seconds at $77 \mathrm{~K}$ (Fig. 1b), demonstrating colour-tunable property of UOP with a low temperature stimulus.

In order to explore the reasons for the colour-tunable UOP of MTOD at low temperature. The photophysical properties of MTOD in the crystal state were first investigated under ambient conditions. As shown in Fig. 2a, the photoluminescence (PL) spectrum of MTOD shows two main emission peaks at 375 and $413 \mathrm{~nm}$ and a shoulder at $435 \mathrm{~nm}$. From the lifetime decay profiles (Fig. S5a†), it was confirmed that they were all assigned to the fluorescence. Notably, the crystals of MTOD presented yellow afterglow after turning off the UV lamp. From the delayed phosphorescence spectrum, the main emission of MTOD was located at 414, 556 and $600 \mathrm{~nm}$ with lifetimes of 681.91, 860.56 and $860.59 \mathrm{~ms}$, respectively (Fig. $2 \mathrm{~b}$ and S5b $\dagger$ ). Among these, the emission around $414 \mathrm{~nm}$ is assigned to triplet-triplet annihilation (TTA) fluorescence originating larger $\pi-\pi$ overlaps of carbazole groups from the crystal data (Fig. S6 $\dagger$ ). ${ }^{26}$ Remaining two emission peaks are attributed to UOP emission. From the phosphorescence excitation-emission spectra of MTOD, UOP can be efficiently excited from 260 to $380 \mathrm{~nm}$, with the optimal excitation at $360 \mathrm{~nm}$ (Fig. S7†).

Subsequently, we measured the PL and phosphorescence spectra of MTOD at $77 \mathrm{~K}$ (Fig. 2a). The steady-state PL spectrum showed four peaks at 361, 376, 410 and $436 \mathrm{~nm}$, with little change compared with its corresponding spectrum at RT. However, a new phosphorescence peak appears at about $480 \mathrm{~nm}$ with an intense emission than others, which displays an ultralong lifetime of $2.5 \mathrm{~s}$. Obviously, the new emission peak plays an indispensable role in the colour-changed UOP at $77 \mathrm{~K}$. The yellowish-white UOP observed by naked eyes at $77 \mathrm{~K}$ is
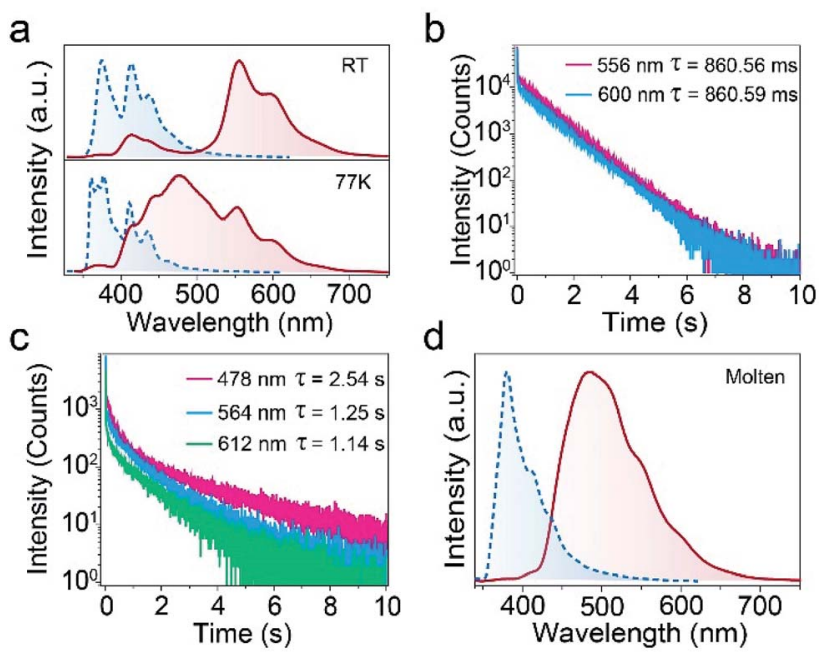

Fig. 2 Photophysical properties of MTOD at room temperature and at 77 K. (a) Steady-state photoluminescence ( $\mathrm{PL}$, blue dashed line) and phosphorescence (red solid line) spectra at RT and $77 \mathrm{~K}$. Inset: photographs taken after removing excitation. (b) Time-resolved phosphorescence decay of the emission bands at 556 and $600 \mathrm{~nm}$ at room temperature, respectively. (c) Time-resolved phosphorescence decay of the emission bands at 478, 564 and $612 \mathrm{~nm}$ at $77 \mathrm{~K}$, respectively. (d) PL (blue dashed line) and phosphorescence (red solid line) spectra at molten state. generated by the combination of three phosphorescence peaks. However, as time goes by, only the blue-green afterglow at about $480 \mathrm{~nm}$ due to the shorter lifetime of long-wavelength phosphorescence can be observed.

To find out the origin of this new peak at $480 \mathrm{~nm}$, the PL and phosphorescence spectra of MTOD at molten state were measured as amorphous emission. As shown in Fig. 2d, the PL peak is located at $380 \mathrm{~nm}$ and the phosphorescence spectrum shows a broad band with a main peak at $484 \mathrm{~nm}$. It is suggested that the new phosphorescence emission peak at $77 \mathrm{~K}$ may be attributed to amorphous state. Taken together, we deduce that the colour-tunable property of the crystal is possibly due to the presence of an amorphous state at low temperature.

The X-ray single crystal diffraction of MTOD crystal was taken to explore the mechanism of UOP at room temperature. Abundant intermolecular and intramolecular interactions (Fig. 3a, S6, S8 and S9a†) in the crystals strongly restrict the torsional molecular configuration. The dihedral angle between the triazine and carbazole groups is about $75^{\circ}$ (Fig. S10 $\dagger$ ). In the crystal of MTOD, the single molecule is limited by multiple intermolecular interactions, including $\mathrm{C}-\mathrm{H} \cdots \mathrm{N}(2.681 \AA), \pi-\mathrm{H} \cdots$ $\pi(2.791,2.876 \AA), \pi-H \cdots N(2.703,2.711 \AA$ ) (Table S3†). The rich intermolecular interactions are beneficial to limit molecular motions to suppress non-radiative transitions of excited molecules, leading to UOP. However, the amorphous molecules around the crystals with weak restriction displayed negligible phosphorescence at room temperature due to the strong motions of alkyl chains.

Comparatively, the single crystal of MTOD molecule at $100 \mathrm{~K}$ was measured in order to explore the colour-changing mechanism of UOP at low temperature (Fig. $3 \mathrm{~b}$ and $\mathrm{S} 9 \mathrm{~b} \dagger$ ). By comparison, MTOD crystals exhibit more intermolecular interactions at $100 \mathrm{~K}$ and the distance become shorter. Molecular conformation of MTOD changed slightly, the dihedral angle between triazine and carbazole changed from $74.95^{\circ}$ to $75.32^{\circ}$ (Fig. S10†). These increased interactions can constrain the molecules more effectively and the stronger restriction of alkyl chain and carbazole will further suppress non-radiative transitions, resulting in the much longer phosphorescence lifetime of over $1.0 \mathrm{~s}$ at low temperature. Compared with the molecules in the crystalline state, freezing condition can provide a more rigid environment to minimize the movement of the alkyl chain, greatly reducing the non-radiative transition rate at amorphous

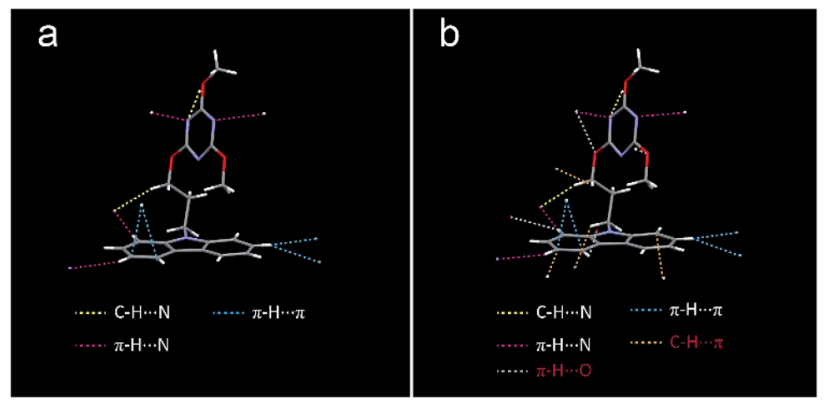

Fig. 3 Intermolecular interactions (a) at room temperature and (b) at $100 \mathrm{~K}$. 

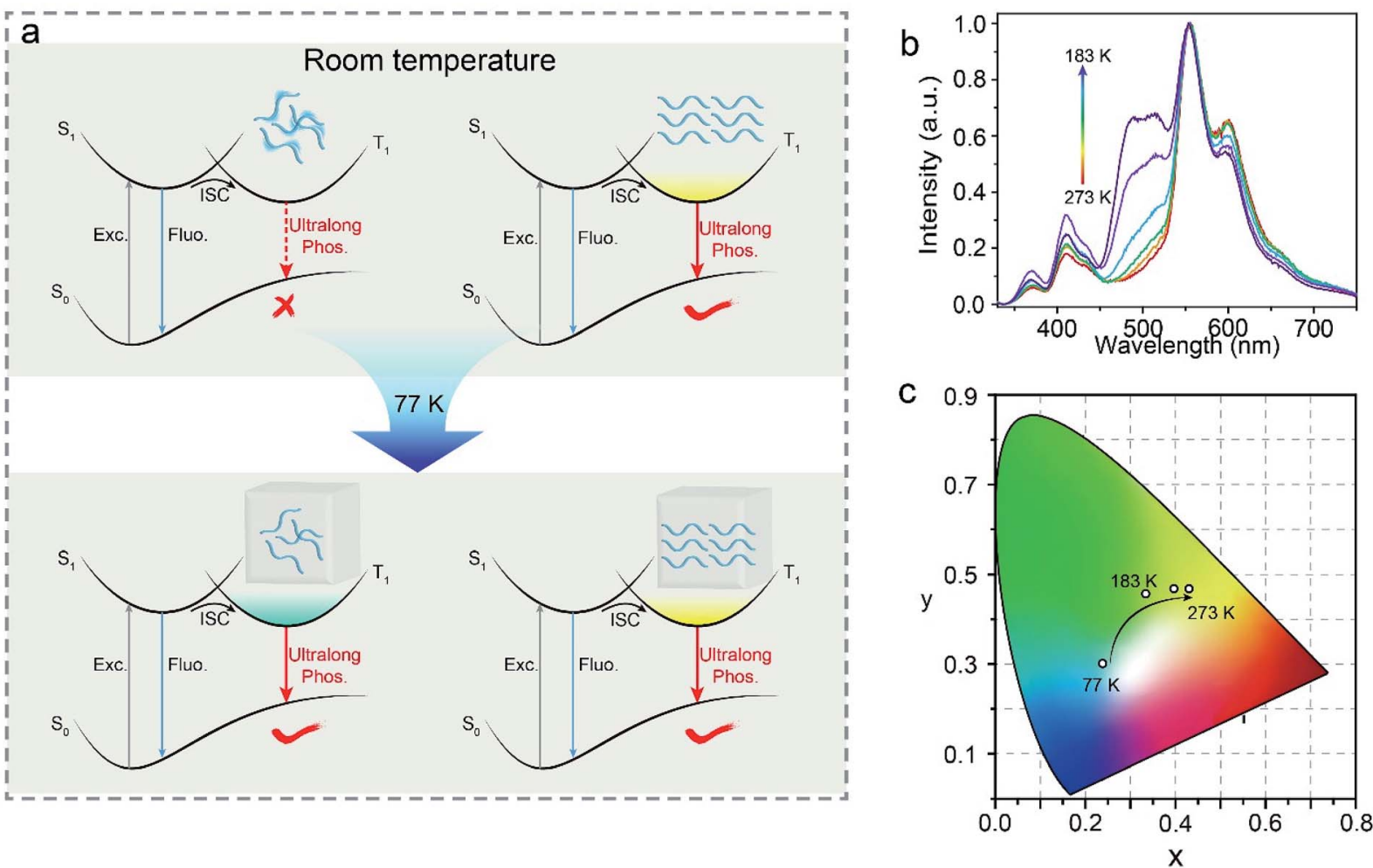

Fig. 4 (a) Jablonski diagram of the relevant photophysical processes illustrating amorphous and crystalline UOP process at room temperature (top) and $77 \mathrm{~K}$ (bottom). (b) Phosphorescence spectra of MTOD at different temperature and (c) corresponding coordinates in CIE.

state, resulting in the lifetime of short wavelength phosphorescence at $478 \mathrm{~nm}$ up to $2.5 \mathrm{~s}$.

According to the above results, the photophysical process of colour-tunable phosphorescence can be described by Jablonski diagram as shown in Fig. 4. Upon photoexcitation, both electrons in amorphous and crystalline molecules transforms to lowest singlet states $\left(\mathrm{S}_{1}\right)$. Then, the electrons in $\mathrm{S}_{1}$ would further transform to the lowest triplet $\left(\mathrm{T}_{1}\right)$ through ISC. At room temperature, amorphous molecules show strong molecular motions to facilitate the non-radiative transitions. However, crystalline molecules due to closely arrangement can exhibit phosphorescence through radiative decay. At $77 \mathrm{~K}$, both excitons in amorphous and crystal states are dominated by radiative transitions, leading to colour-tunable UOP.

In view of the interesting luminescent phenomenon, we have investigated a series of phosphorescent spectra of MTOD crystals at different temperatures ranged from 183 to $273 \mathrm{~K}$. As shown in Fig. 4b, as the temperature increases, the phosphorescence intensity of the amorphous molecules gradually decreases. The colour variations of the MTOD crystals in response to the environmental temperatures are shown in the Commission International de l'Eclairage (CIE) coordinate diagram (Fig. 4c). As the temperature was gradually changed from 183 to $273 \mathrm{~K}$, the UOP changed from green to yellow with good linearity of the CIE coordinates. This demonstrated that MTOD crystals may have potential in low temperature sensing.

In conclusion, we synthesized a colour-tunable singlecomponent UOP compound through alkyl chain engineering.
Combined the spectral and single crystal analyses, it is indicated that colour-tunable UOP comes from dual-emission of molecules at amorphous and crystalline states. Low temperature provides better rigid effect on UOP of amorphous molecules than crystals, resulting in the UOP colour changed from yellow-white to blue-green. More interestingly, red-shifted UOP of MTOD crystals with the increase of temperature can be achieved, demonstrating its potential for temperature sensing. This study will provide a platform for the design of single-component UOP molecules with tunable colour emission and broadens its application field.

\section{Conflicts of interest}

There are no conflicts to declare.

\section{Acknowledgements}

Z. N. and C. M. contributed equally to this work. This work is supported by the National Natural Science Foundation of China (21875104, 51673095, and 21507098), National Basic Research Program of China (973 Program, no. 2015CB932200), Natural Science Fund for Distinguished Young Scholars of Jiangsu Province (BK20180037), the Natural Science Fund for Colleges and Universities (17KJB430020) of Jiangsu Province, and the Natural Science Foundation of Shanxi Province (Grant No. 201801D221340). 


\section{Notes and references}

1 R. Kabe, N. Notsuka, K. Yoshida and C. Adachi, Adv. Mater., 2016, 28, 655.

2 (a) Y. Jing, Q. Cao, L. Hao, G. Yang, W. Hu, L. Ji and Z. Mao, Chem. Commun., 2018, 54, 271; (b) G. Chen, Z. Zhou, H. Feng, C. Zhang, Y. Wang, Z. Qian and J. Pan, Chem. Commun., 2019, 55, 4841.

3 (a) F. Li, F. Wang, X. Hu, B. Zheng, J. Du and D. Xiao, RSC $A d v$., 2018, 8, 16603; (b) D. Lee, O. Bolton, B. C. Kim, J. H. Youk, S. Takayama and J. Kim, J. Am. Chem. Soc., 2013, 135, 6325.

4 (a) K. Jiang, Y. Wang, X. Gao, C. Cai and H. Lin, Angew. Chem., Int. Ed., 2018, 57, 6216; (b) Z. Tian, D. Li, E. V. Ushakova, V. G. Maslov, D. Zhou, P. Jing, D. Shen, S. Qu and A. L. Rogach, Adv. Sci., 2018, 5, 1800795.

5 (a) K. Van den Eeckhout, P. F. Smet and D. Poelman, Materials, 2010, 3, 2536; (b) Z. Xia and A. Meijerink, Chem. Soc. Rev., 2017, 46, 275.

$6 \mathrm{~S} . \mathrm{Xu}, \mathrm{R}$. Chen, C. Zheng and W. Huang, Adv. Mater., 2016, 28, 9920 .

7 (a) H. A. Al-Attar and A. P. Monkman, Adv. Funct. Mater., 2012, 22, 3824; (b) G. Zhang, J. Chen, S. J. Payne, S. E. Kooi, J. N. Demas and C. L. Fraser, J. Am. Chem. Soc., 2007, 129, 8942.

8 (a) Z. An, C. Zheng, Y. Tao, R. Chen, H. Shi, T. Chen, Z. Wang, H. Li, R. Deng, X. Liu and W. Huang, Nat. Mater., 2015, 14, 685; (b) E. Lucenti, A. Forni, C. Botta, L. Carlucci, C. Giannini, D. Marinotto, A. Previtali, S. Righetto and E. Cariati, J. Phys. Chem. Lett., 2017, 8, 1894.

9 (a) Y. Gong, G. Chen, Q. Peng, W. Z. Yuan, Y. Xie, S. Li, Y. Zhang and B. Z. Tang, Adv. Mater., 2015, 27, 6195; (b) J. S. Ward, R. S. Nobuyasu, A. S. Batsanov, P. Data, A. P. Monkman, F. B. Dias and M. R. Bryce, Chem. Commun., 2016, 52, 2612.

10 (a) X. Yang and D. Yan, Chem. Sci., 2016, 7, 4519; (b) H. Mieno, R. Kabe, N. Notsuka, M. D. Allendorf and C. Adachi, Adv. Opt. Mater., 2016, 4, 1015; (c) O. Bolton, K. Lee, H. Kim, K. Y. Lin and J. Kim, Nat. Chem., 2011, 3, 205. 11 (a) W. Chen, Z. Tian, Y. Li, Y. Jiang, M. Liu and P. Duan, Chem. - Eur. J., 2018, 24, 17444; (b) C. Sun, X. Ran, X. Wang, Z. Cheng, Q. Wu, S. Cai, L. Gu, N. Gan, H. Shi, Z. An, H. Shi and W. Huang, J. Phys. Chem. Lett., 2018, 9, 335; (c) G. Baryshnikov, B. Minaev and H. ågren, Chem. Rev., 2017, 117, 6500.

12 L. Zhao, X. Yu, S. Zhang, X. He, L. Li, M. Jia, M. Chang, H. Pan, J. Chen, W. Wang and J. Xu, RSC Adv., 2017, 7, 22684. 13 (a) P. Lehner, C. Staudinger, S. M. Borisov and I. Klimant, Nat. Commun., 2014, 5, 4460; (b) D. Lee, J. Jung, D. Bilby, M. S. Kwon, J. Yun and J. Kim, ACS Appl. Mater. Interfaces,
2015, 7, 2993; (c) C. Zhou, S. Zhang, Y. Gao, H. Liu, T. Shan, X. Liang, B. Yang and Y. Ma, Adv. Funct. Mater., 2018, 28, 1802407.

14 (a) Y. Yang, K. Wang and D. Yan, ACS Appl. Mater. Interfaces, 2017, 9, 17399; (b) P. Xue, J. Sun, P. Chen, P. Wang, B. Yao, P. Gong, Z. Zhang and R. Lu, Chem. Commun., 2015, 51, 10381; (c) B. Xu, H. Wu, J. Chen, Z. Yang, Z. Yang, Y. Wu, Y. Zhang, C. Jin, P. Lu, Z. Chi, S. Liu, J. Xu and M. Aldred, Chem. Sci., 2017, 8, 1909; (d) J. Yang, X. Gao, Z. Xie, Y. Gong, M. Fang, Q. Peng, Z. Chi and Z. Li, Angew. Chem., Int. Ed., 2017, 129, 15501; (e) J. Yang, Z. Ren, Z. Xie, Y. Liu, C. Wang, Y. Xie, Q. Peng, B. Xu, W. Tian, F. Zhang, Z. Chi, Q. Li and Z. Li, Angew. Chem., Int. Ed., 2017, 56, 880; (f) C. Li, X. Tang, L. Zhang, C. Li, Z. Liu, Z. Bo, Y. Q. Dong, Y. Tian, Y. Dong and B. Z. Tang, Adv. Opt. Mater., 2015, 3, 1184.

15 J. Li, J. Zhou, Z. Mao, Z. Xie, Z. Yang, B. Xu, C. Liu, X. Chen, D. Ren, H. Pan, G. Shi, Y. Zhang and Z. Chi, Angew. Chem., Int. Ed., 2018, 130, 6559.

16 Y. Mu, Z. Yang, J. Chen, Z. Yang, W. Li, X. Tan, Z. Mao, T. Yu, J. Zhao, S. Zheng, S. Liu, Y. Zhang, Z. Chi, J. Xu and M. P. Aldred, Chem. Sci., 2018, 9, 3782.

17 Q. Wu, H. Ma, K. Ling, N. Gan, Z. Cheng, L. Gu, S. Cai, Z. An, H. Shi and W. Huang, ACS Appl. Mater. Interfaces, 2018, 10, 33730.

18 Z. He, W. Zhao, J. W. Y. Lam, Q. Peng, H. Ma, G. Liang, Z. Shuai and B. Z. Tang, Nat. Commun., 2017, 8, 416.

19 L. Gu, H. Shi, L. Bian, M. Gu, K. Ling, X. Wang, H. Ma, S. Cai, W. Ning, L. Fu, H. Wang, S. Wang, Y. Gao, W. Yao, F. Huo, Y. Tao, Z. An, X. Liu and W. Huang, Nat. Photonics, 2019, 13, 406.

20 C. Lin, Y. Zhuang, W. Li, T. Zhou and R. Xie, Nanoscale, 2019, 11, 6584 .

21 Z. Cheng, H. Shi, H. Ma, L. Bian, Q. Wu, L. Gu, S. Cai, X. Wang, W. Xiong, Z. An and W. Huang, Angew. Chem., Int. Ed., 2018, 57, 678.

22 G. Zhang, S. E. Kooi, J. N. Demas and C. L. Fraser, Adv. Mater., 2008, 20, 2099.

23 S. Hirata, K. Totani, H. Kaji, M. Vacha, T. Watanabe and C. Adachi, Adv. Opt. Mater., 2013, 1, 438.

24 K. Nagarajan, G. Gopan, R. T. Cheriya and M. Hariharan, Chem. Commun., 2017, 53, 7409.

25 L. Gu, H. Shi, M. Gu, K. Ling, H. Ma, S. Cai, L. Song, C. Ma, H. Li, G. Xing, X. Hang, J. Li, Y. Gao, W. Yao, Z. Shuai, Z. An, X. Liu and W. Huang, Angew. Chem., Int. Ed., 2018, 57, 8425. 26 (a) C. A. M. Salla, G. Farias, M. Rouzières, P. Dechambenoit, F. Durola, H. Bock, B. de Souza and I. H. Bechtold, Angew. Chem., Int. Ed., 2019, 58, 1; (b) A. Ligthart, X. de Vries, L. Zhang, M. C. W. M. Pols, P. A. Bobbert, H. van Eersel and R. Coehoorn, Adv. Funct. Mater., 2018, 28, 1804618. 